\title{
Improved Management of Stillbirth using a Care Pathway.
}

DOI:

10.1108/IJHG-09-2017-0045

\section{Document Version}

Accepted author manuscript

Link to publication record in Manchester Research Explorer

\section{Citation for published version (APA):}

Tomlinson, A. J., Martindale, E. A., Bancroft, K., \& Heazell, A. (2017). Improved Management of Stillbirth using a Care Pathway. International Journal of Health Governance. https://doi.org/10.1108//JHG-09-2017-0045

\section{Published in:}

International Journal of Health Governance

\section{Citing this paper}

Please note that where the full-text provided on Manchester Research Explorer is the Author Accepted Manuscript or Proof version this may differ from the final Published version. If citing, it is advised that you check and use the publisher's definitive version.

\section{General rights}

Copyright and moral rights for the publications made accessible in the Research Explorer are retained by the authors and/or other copyright owners and it is a condition of accessing publications that users recognise and abide by the legal requirements associated with these rights.

\section{Takedown policy}

If you believe that this document breaches copyright please refer to the University of Manchester's Takedown Procedures [http://man.ac.uk/04Y6Bo] or contact uml.scholarlycommunications@manchester.ac.uk providing relevant details, so we can investigate your claim.

\section{OPEN ACCESS}




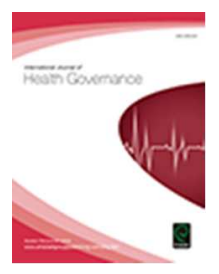

\section{Improved Management of Stillbirth using a Care Pathway.}

\begin{tabular}{|r|l|}
\hline Journal: & International Journal of Health Governance \\
\hline Manuscript ID & ijhg-09-2017-0045 \\
\hline Manuscript Type: & Original Article \\
\hline Keywords: & $\begin{array}{l}\text { Obstetrics < Health Professions, Midwifery < Health Professions, Clinical } \\
\text { effectiveness < Health Service Quality Assurance, Clinical guidelines }< \\
\text { Health Service Quality Assurance, Evidence-based practice < Health } \\
\text { Service Quality Assurance, Teamwork < Health Service Quality Assurance }\end{array}$ \\
\hline \multicolumn{2}{|l}{} \\
\hline
\end{tabular}

SCHOLARONE ${ }^{\text {w }}$

Manuscripts 


\section{Case Study}

Improved Management of Stillbirth using a Care Pathway.

Running Title - Stillbirth Care Pathway

Abstract Word Count - 248 words

Word Count for text of Manuscript $-3,681+3$ Tables +1 Figure 


\begin{abstract}
Purpose - Each year approximately 3,200 women have a stillbirth in the UK. Although national evidence-based guidance has existed since 2010, case reviews continue to identify suboptimal clinical care and communication with parents. Inconsistencies in management include induction and management of labour and the frequency of investigation after stillbirth.
\end{abstract}

Design - An audit of stillbirths was performed in 2014 in 13 maternity units in the North West of England, this confirmed variation in practice described nationally. An integrated care pathway (ICP) was developed from national guidelines to enable optimal care for the management of stillbirth, reduce variation, standardise investigations and coordinate patientfocused care. This was launched in 2015 and updated in 2016 to resolve issues that were apparent after implementation.

Findings - Each participating unit had commenced using the ICP by May 2015. Following implementation there were changes in care, most notably from diverse methods for induction of labour to guideline-directed induction of labour. There were trends towards better care in terms of information given, choices offered, more appropriate analgesia in labour, and improved post-delivery investigation for cause. Staff feedback about the ICP was positive.

Implications - Use of this ICP improved care for women who had a stillbirth and their families. Issues with implementing a changed care pathway meant that further iterations were required, on-going improvement is expected following refinement of the ICP.

Originality - ICPs have been used for various clinical conditions. However, this is the first example of their use in women who had a stillbirth.

Keywords - Stillbirth; Integrated Care Pathway; Perinatal death; Intra-uterine fetal death; Healthcare improvement 


\section{Manuscript}

Introduction

In the UK, approximately 1 in 220 babies are stillborn after 24 weeks of pregnancy which means that in 2015 in England and Wales 3,174 families experienced a stillbirth (Office of National Statistics, 2017). Several national reviews of the quality of maternity care, starting with the 8th Confidential Enquiry into Stillbirths and Deaths in Infancy in 2001 (Confidential Enquiry into Stillbirths and Deaths in Infancy, 2001), have described suboptimal care for parents after stillbirth. In 2010, the Sands Bereavement Care Report noted that "Poor or insensitive care at this traumatic time adds significantly to parents distress. Good care should be universal and should not depend on where a mother happens to live or to be cared for". There is increasing evidence that care lacking in compassion may compound families' distress, whereas good care may give parents positive memories of the short time with their child.(Heazell et al., 2016) The contemporary experience of perinatal bereavement in the UK, was best summarised by one parent in a qualitative study - "There is only one chance to get it right".(Downe et al., 2013) The "Listening to Parents" Report surveyed a sample of 473 parents throughout the UK who had experienced the death of their baby and found that care frequently fell below an acceptable standard.(Redshaw et al., 2014) The report specifically highlighted a number of issues surrounding communication, including that $30 \%$ of parents did not feel listened to or were listened to only "to some extent", their concerns were not always taken seriously or they did not feel wholly informed about what was happening. Less than half of parents felt involved in decision-making and confident about the decisions they made at this time. This may result from the perception parents held that they did not always receive the information they needed after birth; including a quarter who did not receive information about counselling services.

A recent Confidential Enquiry into antepartum stillbirths highlighted concerns about mismanagement of induction of labour following the diagnosis of fetal death leading to 
uterine rupture which is associated with significant maternal morbidity (Draper et al., 2015). Due to a lack of clinical trials there remains uncertainty about the agents and doses of drugs to induce labour following diagnosis of fetal death. Guidance from the Royal College of Obstetricians and Gynaecologists recommends misoprostol over other prostaglandins and oxytocin due to a faster time to delivery (Royal College of Obstetricians and Gynaecologists, 2011). This agent is also recommended by National Institute of Health and Care Excellence (NICE) who suggest that "the choice and dose of vaginal prostaglandins should take into account the clinical circumstances, availability of preparations and local protocols'.(National Collaborating Centre for Women's and Children's Health, 2008)

It was against this background of poor parent experience following stillbirth that a multidisciplinary group of maternity professionals came together with the aim of improving the care for parents who experienced a stillbirth across the geographical footprint of Greater Manchester, Lancashire and South Cumbria (GML\&SC), an ethnically and socially diverse region which has historically had a stillbirth rate above the UK national average.(Manktelow et al., 2015)

Initial Assessment

The timeline for the quality improvement project is shown in Table 1. A multi-professional group consisting of Obstetricians, Midwives and Perinatal Pathologists from all 13 hospitalbased maternity units in Greater Manchester, Lancashire and South Cumbria was convened. The group agreed that the national issues identified were also issues locally. Relevant national guidance, including the Royal College of Obstetricians and Gynaecologists Clinical Guideline for the "Management of Late Intrauterine Death and Stillbirth" was identified and the current literature was reviewed and the evidence base for each recommendation made. During the initial period two exercises were undertaken.

Firstly, all hospital-based maternity units in the region were surveyed to determine which of the 139 recommendations in the RCOG Guideline were perceived to be relevant and able to 
be implemented. This was achieved by asking obstetricians and midwives to rank each item of clinical guidance using a Likert scale from 1 to 5 where 1 was the lowest level of relevance or ability to implement and 5 was deemed to be highly relevant or simple to implement. Of the responses obtained 116 of the 139 recommendations were thought to be highly relevant of which 113 were thought to be able to be implemented within the health care settings of the maternity units involved.

Secondly, an audit of care of for stillbirths was undertaken, evaluating practice against the standards identified from the RCOG guidance to assess if the recommendations were being incorporated into current practice. Each of the 13 maternity units was asked to contribute at least 2 cases to the audit, in total 29 cases were submitted. In this audit details about medical and obstetric history were obtained as well as information about presentation during the episode when intra-uterine fetal death was diagnosed, which included information about management both in terms of medical treatments given, investigations performed to identify the cause of the stillbirth, outcomes and specific items relating to information given to women and their partners. The findings of this baseline (2014) audit are detailed in Table 2, but demonstrate that women were infrequently given high quality information, to offer them choices about management (where appropriate). Importantly, medical management, particularly induction of labour and analgesia during labour, did not follow national guidance.

\section{Choice of Solution}

An Integrated Care Pathway (ICP) was chosen as the initial method to improve the quality of care as they have been shown to reduce risks, increase patient satisfaction and increase the efficiency in the use of resources,(De Bleser et al., 2006, Panella et al., 2003) as well as improving staff experience.(Kent and Chalmers, 2006) Allen et al. noted that ICPs could be most beneficial where there are identified deficiencies in services, but their value in established multidisciplinary working was less clear.(Allen et al., 2009) A systematic review have shown beneficial effects of use of ICPs including reduced in-hospital complications, 
improved documentation and reduced length of stay.(Rotter et al., 2010) ICPs are used for many different and diverse conditions including orthopaedics,(Olsson et al., 2006) respiratory (Norrie et al., 2016) and neurological conditions.(Abdul et al., 2014) A literature search undertaken by one author in 2014 did not identify any publications which had used ICPs in Obstetrics, although this had been used for a diverse range of conditions in gynaecology (Letton et al., 2013, Graham et al., 2010, Julian et al., 2007, Jha et al., 2007) and in neonatal care.(Rogerson et al., 2004) Reflecting upon the available evidence an ICP was determined to be the best solution in order to formalise the care process to reduce clinical risks and increase participant satisfaction. A clinical guideline was also written to support the ICP to give background and cite the underlying evidence for the interventions and facilitate use of the ICP in individual units. Both documents were written by a multidisciplinary team which aimed to incorporate the evidence based recommendations ranked by the regional appraisal of the RCOG guideline.

\section{Implementation}

The Guideline and ICP were developed iteratively and authorised by the regional Maternity Steering Group (Greater Manchester, Lancashire and South Cumbria Strategic Clinical Network). Maternity staff were invited to a launch event was held in December 2014; the meeting was attended by a multi-professional audience representing all of the maternity units in the region. Physical copies of the ICP and the clinical guideline were then delivered to each unit and an implementation visits undertaken by two authors (AJT) to resolve any issues. Each of the 13 units in the region gave a commitment to implement the documents in the timeframe from February to June 2015 and to enter data for an annual audit of cases. The ICP and clinical guideline were implemented in all maternity units in the region by June 2015. 


\section{Evaluation}

The impact of the ICP and clinical guideline was assessed by a series of regional audits. In the baseline audit, hospital-based maternity units were asked to enter the first 2 cases of stillbirth occurring after $1^{\text {st }}$ July 2014 . Maternity units were asked to enter data from the first two cases of stillbirth after the implementation of the ICP in an attempt to capture an unbiased sample. To assess ongoing effectiveness of the ICP, units were asked to report the first two cases of stillbirth occurring after $1^{\text {st }}$ January 2016. The audit questionnaire (Supplementary File 1) recorded clinical information about the stillbirth (gestation, cause), the care from diagnosis, management of labour/delivery, investigation of cause through to the postnatal appointment. There was also a free text area for any comments that those inputting the data could make observations on the ICP. The audit questionnaire was modified after the initial audit, as some data items were not used in analysis, the number of questions asked were reduced to facilitate completion of the audit by staff in participating maternity units. Audit data were processed in Microsoft Excel using the QICharts Add-In (QI-Charts v. 1.0.39, Scoville Associates).

In the baseline audit, 12 of the 13 units participated, inputting a total of 29 cases (one unit entered three cases and two units entered four cases). The remaining unit had no stillbirths in the timeframe requested. In 2015, 11 units participated, inputting a total of 40 cases, although following removal of duplicate and incomplete cases, 29 reports were included in the audit. In 2016, 10 units participated, recording care given in 31 cases. Data regarding the number of cases included in the audit, the average gestation and the recorded cause of stillbirth are shown in Table 2. Although there was variation in the case mix included in the regional audit, the gestation and causes of stillbirth were comparable to previous studies (Cockerill et al., 2012). 


\section{Evaluation Results}

Following implementation there were variable changes in care (shown in Table 3). Where standards of care were already well established such as the use of ultrasound for diagnosis of labour, post-mortem being offered to parents or lactation suppression (Figures 1A, 1E and Table 3) compliance remained high. Furthermore, when these standards were not met there were underlying clinical reasons e.g. lactation suppression not given as there was a surviving twin. The frequency of using information leaflets to describe what happens following the diagnosis of fetal death or to provide information about post-mortem increased (Figure 1B and Table 3), although a record of giving specific information such as the presence of passive movements did not increase. The greatest change was from diverse methods for induction of labour to guideline-directed drugs and dosages induction of labour (Figure 1C) and increased frequency of the use of Diamorphine (recommended due to better analgesic effect) rather than Pethidine, from a 2:1 ratio in 2014 to a 5:1 ratio in 2016 (Figure 1D). Followup with an obstetrician was more frequent using the new guideline, and there was greater multidisciplinary team working with evidence that a bereavement midwife was present as well as an obstetric consultant in $35 \%$ of consultations. There was also an improvement in the notification of a stillbirth as a clinical incident. Staff feedback has been positive, as illustrated by the following quote "The new care pathway is such an improvement..., it is a comprehensive, logical and well-presented document that tells you what to do - this makes it less daunting for the midwives, as they are usually overwhelmed by several individual pieces of paper." Other comments identified further areas for improvement of the ICP such as "No area on the ICP for recording discussion of passive movements or expectant management. These things are often not documented and could be included in future versions of the ICP" and "Give examples of how to complete a certificate of stillbirths correctly, e.g. clinical scenarios". 


\section{Discussion}

Evaluation of this quality improvement project suggests that an ICP can improve some aspects of practise and standardise care delivered after the diagnosis of fetal death. The results suggest that practice in this region is comparable or significantly exceeds national practice. For example, $97 \%$ of women received lactation suppression compared to $37 \%$, and a follow-up visit conducted in $90 \%$ of cases compared to $66 \%$ in the recent Confidential Enquiry into Antepartum Stillbirth (Draper et al., 2015). The observed improvements are in keeping with studies of ICPs in other areas that demonstrate evidence for improvement, particularly in documentation (Rotter et al., 2010). The increased evidence for information giving may also underpin enhanced patient experience (De Bleser et al., 2006, Panella et al., 2003). In addition, the ICP received positive feedback from staff which is in agreement with previous evidence of improved staff experience (Kent and Chalmers, 2006).

The largest improvement in practice occurred with respect to methods of induction of labour. This is an area of contemporary practice where there is limited evidence to determine "gold standard" practice, with NICE guidelines recommending administration according to local protocol. This is made even more challenging as administration of misoprostol is off-label. Therefore, the ICP and guideline have introduced a regional framework leading to a consistent management in the cases audited and thus variation has been reduced which may translate into increased safety. The regime was effective in achieving vaginal delivery in 16 of the 17 women in 2016 , the case that was unsuccessful was a case of significant fetal malformation, where a feticide was performed and induction commenced following that procedure.

It is notable that the positive effect of the ICP took time to emerge, reflecting the fact that developing an ICP was part of an iterative quality-improvement process, rather than being an end in itself. Audit was essential to this process as mechanisms to capture variance allow further development of the pathway (Kitchiner et al., 1996). However, the audit did not allow- 
ance for variances some of which could have been for good clinical reasons e.g. omission of lactation suppression due to a surviving twin. In such cases, detailed case review with documentation of the reasons for deviation from the ICP would be more informative. Contact with the units during the implementation of the ICP and guideline was essential as this identified practical issues with the pathway and identification of solutions as units developed work rounds to overcome the issues. This modification was needed in spite of wide circulation and adaptation in response to comments prior to the implementation phase. The ICP was updated in December 2015 and the further development may explain the increase in compliance with some of the audit criteria in 2016 compared to 2015.

Variation in care pathways is evident in other areas of maternity care; a study of 17 pathways for normal birth in a region of Belgium found differences in the layout and evidencebased content, with $59 \%$ containing fewer than half of the centrally defined evidence-based recommendations for normal birth (Sarrechia et al., 2013). This variation in care provided in geographic regions can lead to challenges when a mother moves from one care provider to another (Mills et al., 2016) which frequently occurs in pregnancies following stillbirth, emphasising the need for coordinated care in order that appropriate investigations are undertaken to determine the cause of stillbirth and a plan made for subsequent pregnancy. There have been mixed experiences of care pathways in maternity care, with one document to promote normal birth in Wales eliciting mixed reactions; both midwives and doctors considered that the pathway had increased interprofessional tensions and there was no evidence that it had achieved its desired results (Hunter and Segrott, 2010). This is in direct contrast to our experience, where the stillbirth ICP pathway facilitated multidisciplinary working and appeared to improve clinical outcomes. The success of the stillbirth ICP may result from continued involvement in all stakeholder organisations and professional groups from the outset of the project, which should be considered for similar quality improvement projects in future. 


\section{References}

ABDUL, A. A., MUHAMMAD NUR, A., SULONG, S. \& ALJUNID, S. 2014. The Integrated Care Pathway for Managing Post Stroke (ICAPPS) Patients in the Community: A Cost -Effectiveness Analysis. Value Health, 17, A761.

ALLEN, D., GILLEN, E. \& RIXSON, L. 2009. Systematic review of the effectiveness of integrated care pathways: what works, for whom, in which circumstances? Int J Evid Based Healthc, 7, 61-74.

COCKERILL, R., WHITWORTH, M. K. \& HEAZELL, A. E. 2012. Do medical certificates of stillbirth provide accurate and useful information regarding the cause of death? Paediatr Perinat Epidemiol, 26, 117-23.

CONFIDENTIAL ENQUIRY INTO STILLBIRTHS AND DEATHS IN INFANCY 2001. 8th Annual Report, 1 January-31 December 1999. London: Maternal and Child Health Research Consortium.

DE BLESER, L., DEPREITERE, R., DE WAELE, K., VANHAECHT, K., VLAYEN, J. \& SERMEUS, W. 2006. Defining pathways. J Nurs Manag, 14, 553-63.

DOWNE, S., SCHMIDT, E., KINGDON, C. \& HEAZELL, A. E. 2013. Bereaved parents' experience of stillbirth in UK hospitals: a qualitative interview study. BMJ Open, 3.

DRAPER, E. S., KURINCZUK, J. J., KENYON, S. \& MBRRACE-UK., O. B. O. 2015. MBRRACE-UK Perinatal Confidential Enquiry: Term, singleton, normally formed, antepartum stillbirth. Leicester: The Infant Mortality and Morbidty Studies, Department of Health Sciences, University of Leicester.

GRAHAM, O., JAYADEVA, P. \& GUTHRIE, K. 2010. The use of an integrated care pathway for evidence-based practice and clinical governance in abortion care. $J$ Obstet Gynaecol, 30, 397-403.

HEAZELL, A. E., SiAssakos, D., Blencowe, H., BURDEN, C., BHUTTA, Z. A., CACCIATORE, J., DANG, N., DAS, J., FLENADY, V., GOLD, K. J., MENSAH, O. K., MILLUM, J., NUZUM, D., O'DONOGHUE, K., REDSHAW, M., RIZVI, A., ROBERTS, 
T., TOYIN SARAKI, H. E., STOREY, C., WOJCIESZEK, A. M. \& DOWNE, S. 2016. Stillbirths: economic and psychosocial consequences. Lancet, 387, 604-16.

HUNTER, B. \& SEGROTT, J. 2010. Using a clinical pathway to support normal birth: impact on practitioner roles and working practices. Birth, 37, 227-36.

JHA, S., MORAN, P., BLACKWELL, A. \& GREENHAM, H. 2007. Integrated care pathways: the way forward for continence services? Eur J Obstet Gynecol Reprod Biol, 134, $120-5$.

JULIAN, S., NAFTALIN, N. J., CLARK, M., SZCZEPURA, A., RASHID, A., BAKER, R., TAUB, N. \& HABIBA, M. 2007. An integrated care pathway for menorrhagia across the primary-secondary interface: patients' experience, clinical outcomes, and service utilisation. Qual Saf Health Care, 16, 110-5.

KENT, P. \& CHALMERS, Y. 2006. A decade on: has the use of integrated care pathways made a difference in Lanarkshire? J Nurs Manag, 14, 508-20.

KITCHINER, D., DAVIDSON, C. \& BUNDRED, P. 1996. Integrated care pathways: effective tools for continuous evaluation of clinical practice. J Eval Clin Pract, 2, 65-9.

LETTON, C., CHEUNG, C. \& NORDIN, A. 2013. Does an enhanced recovery integrated care pathway (ICP) encourage adherence to prescribing guidelines, accelerate postoperative recovery and reduce the length of stay for gynaecological oncology patients? J Obstet Gynaecol, 33, 296-7.

MANKTELOW, B. M., SMITH, L. K., EVANS, T. A., HYMAN-TAYLOR, P., KURINCZUK, J. J., FIELD, D. J., SMITH, P. W., DRAPER, E. S. \& ON BEHALF OF THE MBRRACEUK COLLABORATION 2015. Perinatal Mortality Surveillance Report - UK Perinatal Deaths for births from January to December 2013. . Leicester:: The Infant Mortality and Morbidity Group, Department of Health Sciences, University of Leicester.

MILLS, T. A., RICKLESFORD, C., HEAZELL, A. E., COOKE, A. \& LAVENDER, T. 2016. Marvellous to mediocre: findings of national survey of UK practice and provision of 
care in pregnancies after stillbirth or neonatal death. BMC Pregnancy Childbirth, 16, 101.

NATIONAL COLLABORATING CENTRE FOR WOMEN'S AND CHILDREN'S HEALTH 2008. Induction of Labour. 2nd edition ed. London Royal College of Obstetricians and Gynaecologists.

NORRIE, O. S., DZIADEKWICH, R., FERNANDEZ, R. \& METGE, C. J. 2016. Chronic Obstructive Pulmonary Disease (COPD) Integrated Care Pathway Project: Evaluation of Patient Outcomes and System Efficiencies. J Popul Ther Clin Pharmacol, 23, e169-e182.

OFFICE OF NATIONAL STATISTICS 2017. Births and Deaths in England and Wales 2016. Fareham, Hampshire: Office of National Statistics.

OLSSON, L. E., KARLSSON, J. \& EKMAN, I. 2006. The integrated care pathway reduced the number of hospital days by half: a prospective comparative study of patients with acute hip fracture. J Orthop Surg Res, 1, 3.

PANELLA, M., MARCHISIO, S. \& DI STANISLAO, F. 2003. Reducing clinical variations with clinical pathways: do pathways work? Int J Qual Health Care, 15, 509-21.

REDSHAW, M., ROWE, A. \& HENDERSON, J. 2014. Listening to parents after stillbirth or the death of their baby after birth. Oxford, UK: Policy Research Unit in Maternal Health and Care, National Perinatal Epidemiology Unit.

ROGERSON, S., MALENGA, G. \& MOLYNEUX, E. M. 2004. Integrated care pathways: a tool to improve infant monitoring in a neonatal unit. Ann Trop Paediatr, 24, 171-4.

ROTTER, T., KINSMAN, L., JAMES, E., MACHOTTA, A., GOTHE, H., WILLIS, J., SNOW, P. \& KUGLER, J. 2010. Clinical pathways: effects on professional practice, patient outcomes, length of stay and hospital costs. Cochrane Database Syst Rev, CD006632.

ROYAL COLLEGE OF OBSTETRICIANS AND GYNAECOLOGISTS 2011. Late Intrauterine Fetal Death and Stillbirth London: RCOG. 
SARRECHIA, M., VAN GERVEN, E., HERMANS, L., DENECKERE, S., SERMEUS, W., PANELLA, M., SPITZ, B. \& VANHAECHT, K. 2013. Variation in 17 obstetric care pathways: potential danger for health professionals and patient safety? $J$ Adv Nurs, $69,278-85$.

Figure $1-\mathrm{P}$ charts demonstrating changes in clinical practice following the implementation of the stillbirth ICP. The proportion of appropriate cases where A) Ultrasound was used for diagnosis B) Women received an information leaflet, C) An appropriate dose of misoprostol was used for induction of labour, D) Diamorphine was used for analgesia, E) Lactation suppression was used and F) An Incident Form was completed. UCL = Upper confidence limit, $L C L=$ Lower confidence limit.

Table 1 - Project Timeline

\begin{tabular}{|l|l|}
\hline Time & Activity \\
\hline April 2013 - October 2013 & Project set-up, regional guideline audit and review \\
\hline October 2013 -November 2013 & $\begin{array}{l}\text { Specialist Interest Group formalised. Project Manager } \\
\text { appointed. }\end{array}$ \\
\hline March 2014 & Clinical Project Lead appointed. \\
\hline April 2014 - July 2014 & Initial ICP document developed. Baseline audit. \\
\hline July 2014 - September 2014 & Consultation period on ICP. Baseline audit. \\
\hline September 2014 - November 2014 & ICP finalised. Audit evaluated. \\
\hline December 2014 & Regional launch event for ICP and guideline. \\
\hline January 2015 - April 2015 & Implementation period. Site visits. \\
\hline June 2015 - July 2015 & Post-implementation audit \\
\hline August 2015 - November 2015 & Analysis of audit data. Revision of ICP and guideline \\
\hline December 2015 & Regional education event \\
\hline July 2016 - August 2016 & Audit of progress \\
\hline
\end{tabular}


Table 2 - Number and Characteristics of Cases included in baseline audit and evaluation of the ICP. Data presented as number with percentage in parentheses, or median (range) for gestation of stillbirth.

\begin{tabular}{|c|c|c|c|}
\hline $2=$ & \multicolumn{3}{|c|}{ Year } \\
\hline Characteristic & 2014 (Baseline) & 2015 & 2016 \\
\hline $\begin{array}{l}\text { Number of stillbirths audited with } \\
\text { complete data }\end{array}$ & 29 & 29 & 31 \\
\hline $\begin{array}{l}\text { Number of cases requiring } \\
\text { customised management }\end{array}$ & $10(34)$ & $15(52)$ & $8(26)$ \\
\hline $\begin{array}{l}\text { Number of cases requiring } \\
\text { induction of labour }\end{array}$ & $17(59)$ & $16(55)$ & $17(55)$ \\
\hline Gestation of Stillbirth (range) & $36^{+6}\left(24^{+6}-41^{+5}\right)$ & $32^{+5}\left(24^{+2}-41^{+1}\right)$ & $35^{+0}\left(24^{+1}-41^{+5}\right)$ \\
\hline \multicolumn{4}{|l|}{$\begin{array}{l}\text { Cause of Stillbirth (Primary } \\
\text { ReCoDe) }\end{array}$} \\
\hline Lethal Congenital Anomaly & $1(3)$ & $3(10)$ & $4(13)$ \\
\hline Acute Infection & $2(7)$ & $2(7)$ & $0(0)$ \\
\hline Twin to Twin Transfusion & $0(0)$ & $1(3)$ & $0(0)$ \\
\hline Fetal Growth Restriction & $10(34)$ & $4(14)$ & $2(6)$ \\
\hline Other Fetal Condition & $0(0)$ & $1(3)$ & $0(0)$ \\
\hline Umbilical Cord Prolapse & $0(0)$ & $1(3)$ & $0(0)$ \\
\hline Constricting loop or knot of cord & $1(3)$ & $2(7)$ & $2(6)$ \\
\hline Placental Abruption & $3(10)$ & $4(14)$ & $2(6)$ \\
\hline Placental Insufficiency & $3(10)$ & $3(10)$ & $7(23)$ \\
\hline Chorioamnionitis & $0(0)$ & $0(0)$ & $3(10)$ \\
\hline Uterine rupture & $0(0)$ & $1(3)$ & $0(0)$ \\
\hline Diabetes & $0(0)$ & $0(0)$ & $2(6)$ \\
\hline $\begin{array}{l}\text { Hypertensive disorder of } \\
\text { pregnancy }\end{array}$ & $0(0)$ & $0(0)$ & $1(3)$ \\
\hline Intrapartum Asphyxia & $1(3)$ & $0(0)$ & $0(0)$ \\
\hline No relevant condition identified & $8(28)$ & $6(21)$ & $5(16)$ \\
\hline Insufficient information available & $0(0)$ & $1(3)$ & $3(10)$ \\
\hline
\end{tabular}


Table 3 - Number and proportion of cases meeting audit standards in baseline audit and evaluation of the ICP. Data presented as number with percentage in parentheses, where this was not calculated using the total number of cases the relevant denominator is stated.

\begin{tabular}{|c|c|c|c|}
\hline & \multicolumn{3}{|c|}{ Year } \\
\hline Audit criteria & $\begin{array}{c}2014 \\
\text { (Baseline) }\end{array}$ & 2015 & 2016 \\
\hline Number of stillbirths audited with complete data & 29 & 29 & 31 \\
\hline Clinical Incident Notified & $22(76)$ & $26(90)$ & $31(100)$ \\
\hline Ultrasound used to diagnose fetal death & $27(93)$ & $25(86)$ & $30(97)$ \\
\hline $\begin{array}{l}\text { Patient information leaflet given } \\
\text { (\% of women with non-emergency management) }\end{array}$ & $3(16)$ & $6(38)$ & $15(65)$ \\
\hline $\begin{array}{l}\text { Women informed about passive movements } \\
\text { (\% of women with non-emergency management) }\end{array}$ & $2(11)$ & $2(13)$ & $3(74)$ \\
\hline $\begin{array}{l}\text { Wishes regarding birth documented } \\
\text { (\% of women with non-emergency management) }\end{array}$ & $10(53)$ & $13(81)$ & $17(74)$ \\
\hline $\begin{array}{l}\text { Mifepristone given prior to induction of labour } \\
\text { (\% of women undergoing induction of labour) }\end{array}$ & $17(100)$ & $15(94)$ & $17(100)$ \\
\hline $\begin{array}{l}\text { Appropriate dose of misoprostol prescribed } \\
\text { (\% of women undergoing induction of labour) }\end{array}$ & $6(35)$ & $8(50)$ & $16(94)$ \\
\hline $\begin{array}{l}\text { Proportion of women receiving Diamorphine for } \\
\text { analgesia }\end{array}$ & $9(33)$ & $10(55)$ & $14(82)$ \\
\hline Post-mortem (PM) offered & $28(97)$ & $29(100)$ & $29(94)$ \\
\hline Information leaflet for PM given & $21(72)$ & $17(59)$ & $26(84)$ \\
\hline Post-mortem conducted & $1(3)$ & $12(41)$ & $14(45)$ \\
\hline Placental histological examination & $27(93)$ & $23(79)$ & $27(87)$ \\
\hline $\begin{array}{l}\text { Placental histological examination by specialist } \\
\text { perinatal / placental pathologist ( } \% \text { of placental } \\
\text { examinations) }\end{array}$ & $15(55)$ & $14(61)$ & $26(96)$ \\
\hline Lactation suppression & $27(93)$ & $28(97)$ & $31(100)$ \\
\hline Follow-up visit & $24(83)$ & $25(86)$ & $28(90)$ \\
\hline
\end{tabular}


1

2

3

4

5

6

7

8

9

10

11

12

13

14

15

16

17

18

19

20

21

22

23

24

25

26

27

28

29

30

31

32

33

34

35

36

37

38

39

40

41

42

43

44

45

46

47

48

49

50

51

52

53

54

55

56

57

\section{A Proportion of Cases when Ultrasound used for Diagnosis}

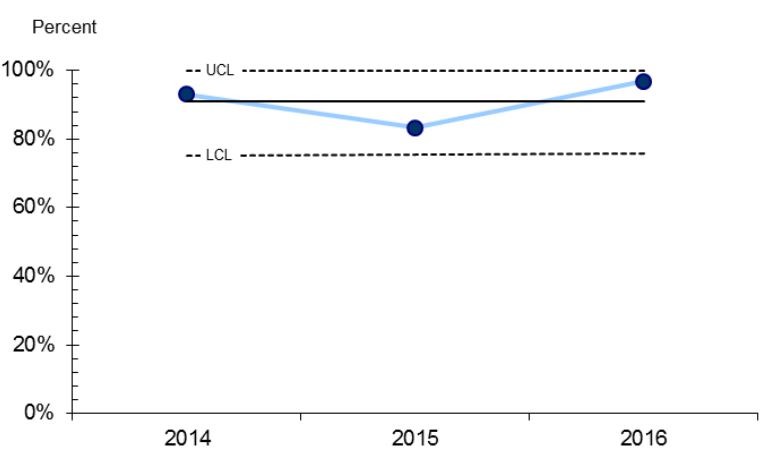

C Proportion of Women undergoing Induction of C Labour Recieving Appropriate Dose of Misprostol Percent
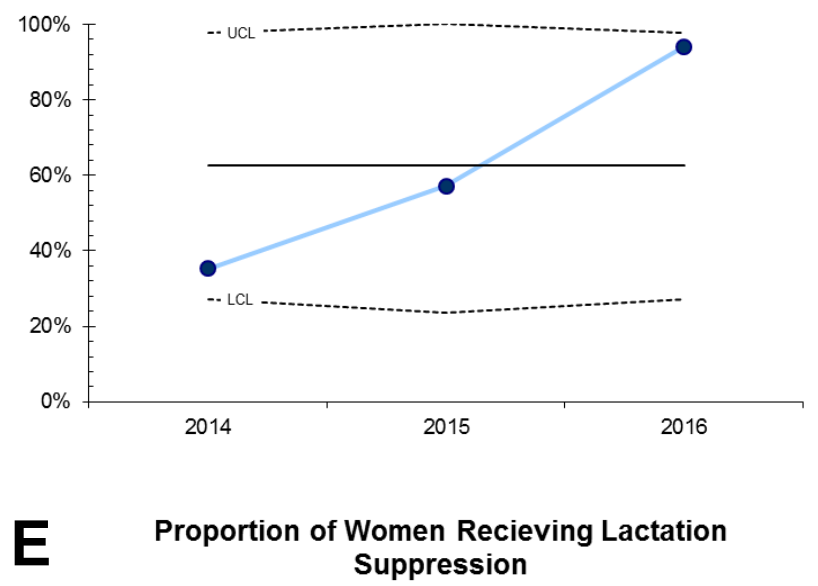

Percent
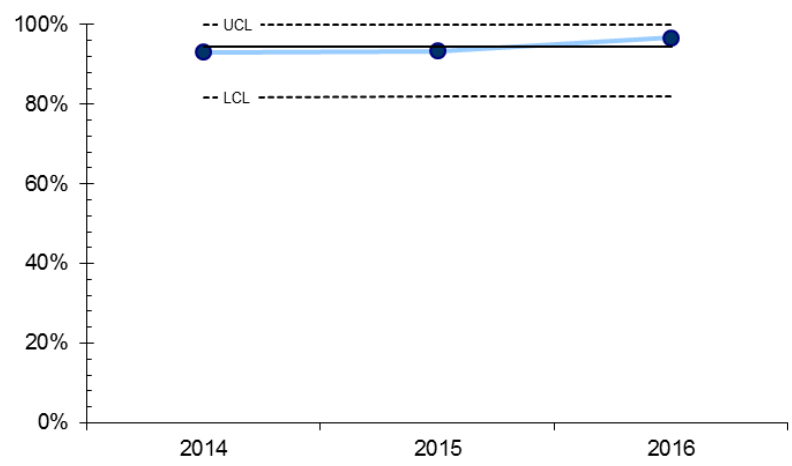

B

Proportion of Women Receiving Information Leaflet

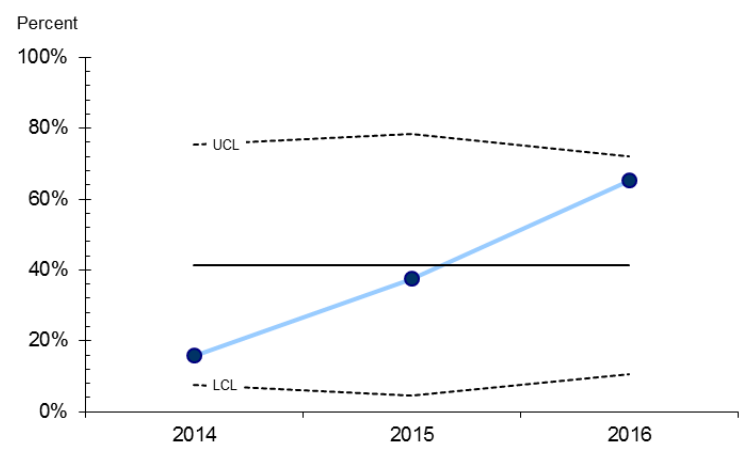

D

Proportion of Women Recieving Diamorphine

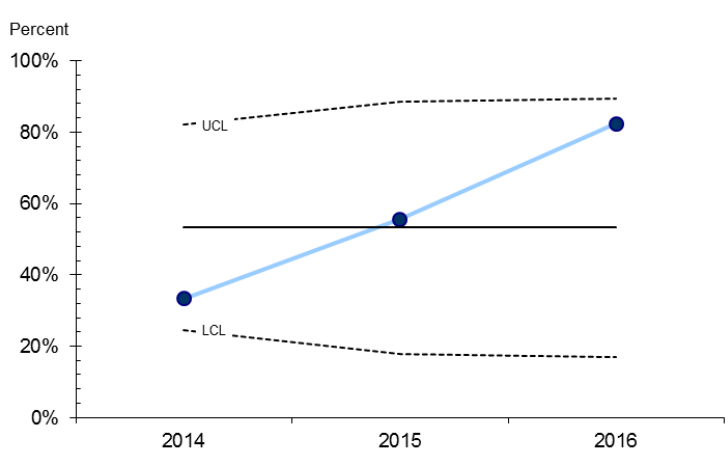

$\mathbf{F}$

Proportion of Cases with Completed Incident Form

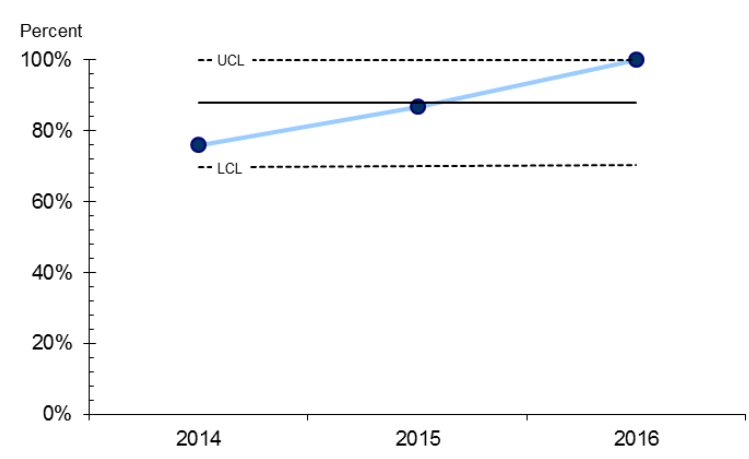


1. Which maternity unit are you from?

$\begin{array}{ll}\text { Barrow in Furness } & \text { North Manchester } \\ \text { Blackpool } & \text { Oldham } \\ \text { Bolton } & \text { Preston } \\ \text { East Lancashire } & \text { St Mary's Hospital } \\ \text { Lancaster } & \text { Stockport } \\ \text { Other (please specify) } & \end{array}$

\section{North-West Regional Stillbirth Audit 2016}

2. Was an incident form completed for the stillbirth?

Not recorded

Yes

No

3. What was the ethnicity of the mother?

White British

White Irish

White Other

Indian

Pakistani

Bangladeshi

Other Asian Ethnic Group

Black Caribbean
Black African

Other Black Ethnic Group

Chinese

Mixed origin White and Black Caribbean

Mixed origin White and Black African

Mixed origin White and Asian

Any other ethnic group

Not stated 


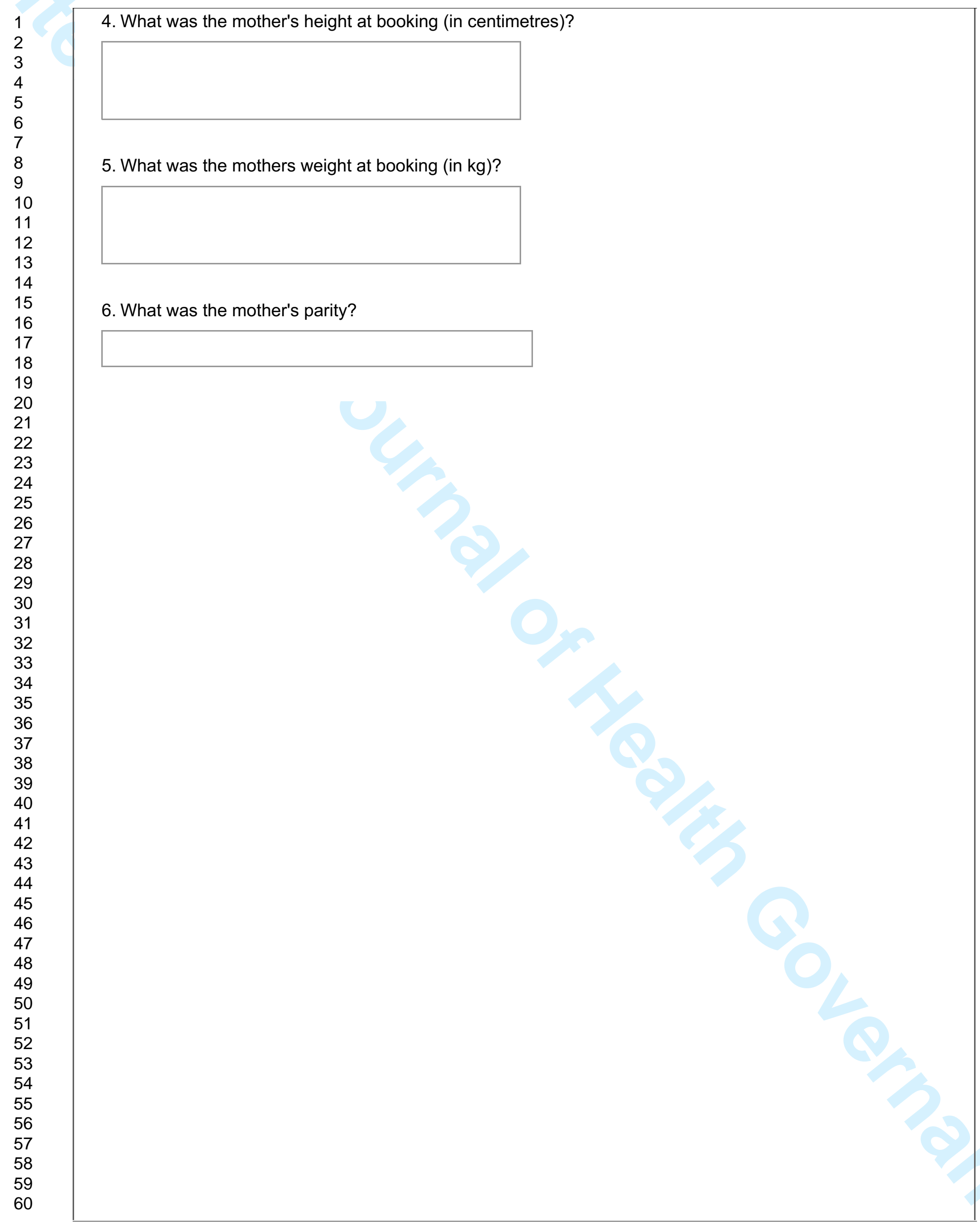


7. Was the affected pregnancy single or multiple? 
8. What was the chorionicity of the multiple pregnancy?

9. How many babies died? (e.g. if one twin died enter 1 , if two of three triplets died enter 2). If more than one baby died please complete an audit form for each death.

10. When was fetal death in utero diagnosed?

Antepartum

Intrapartum
Uncertain

Termination of Pregnancy (Time of diagnosis not applicable) 
11. Did the mother have any of the following symptoms or signs at presentation?

$\square$ Antepartum haemorrhage

Decreased fetal movements

Hypertension / Preeclampsia

Other (please specify)

North-West Regional Stillbirth Audit 2016

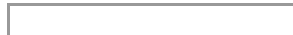

12. Was ultrasound used for diagnosis?

Yes

If no, please state why.

13. Who made the diagnosis?
Sonographer
Obstetrician (ST 6-7)
Obstetrician (ST 1-2)
Staff Grade Obstetrician
Obstetrician (ST 3-5)
Consultant Obstetrician

Midwife sonographer

14. Was the diagnosis of FDIU confirmed by a second person?

Yes

No 
15. Who confirmed the diagnosis?

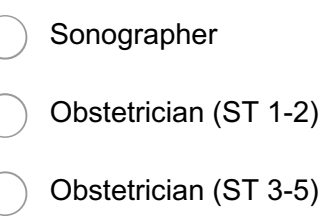

\section{North-West Regional Stillbirth Audit 2016}

for families who have

experienced a stillbirth.

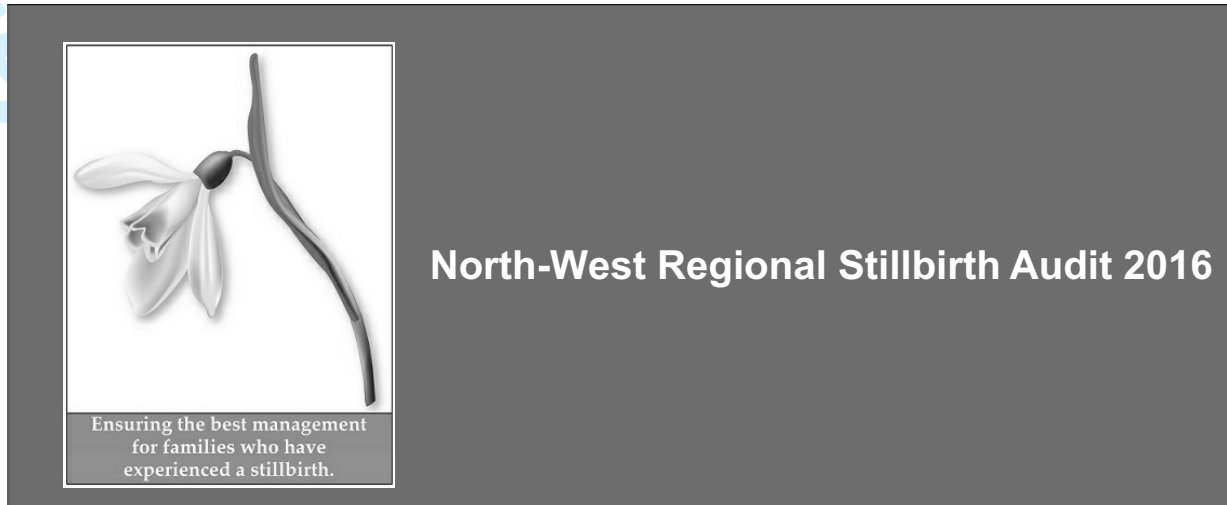

16. What was the time that the diagnosis of FDIU was confirmed?

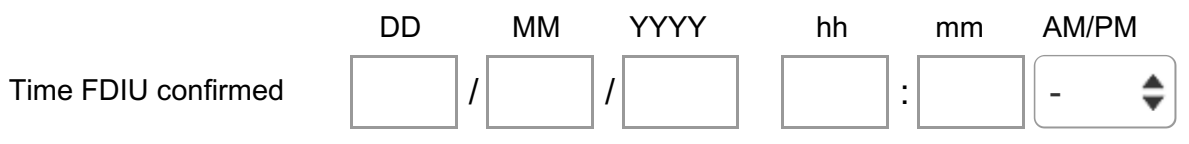

17. Which investigations were performed at diagnosis of FDIU? (Tick all that apply)

Full blood count

$\square$ Liver Function Tests

Clotting screen (PT/APTT)

Kleihauer

Urea and electrolytes

Group and Save

18. Was a patient information leaflet given to the parents after diagnosis?
Yes
No
Not recorded 
19. Were the parents informed of the possibility of passive movements?
Yes
Not appropriate
No
Not recorded

If not appropriate, please state why

20. Was there an indication for immediate delivery?

Yes

If Yes (Please state indication in comment box) 


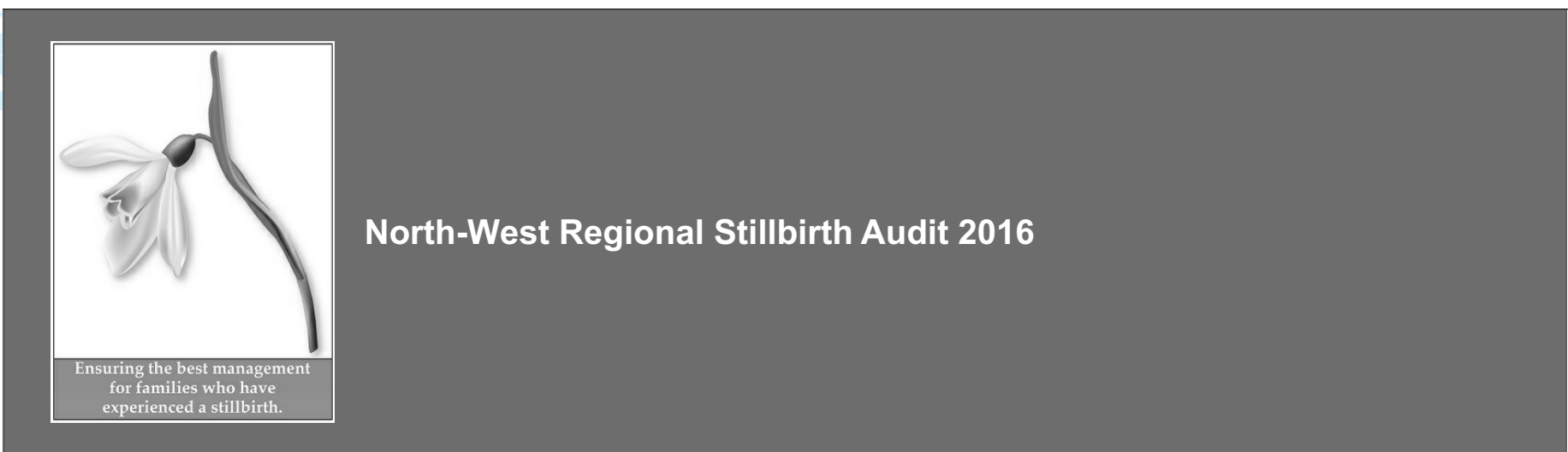

21. Was expectant management offered?
Yes
N/A Ongoing multiple pregnancy

No 


\section{Plan for birth}

\section{North-West Regional Stillbirth Audit 2016}

22. Were the mother (or parents) wishes regarding delivery documented? Yes

23. Did the patient have a previous Caesarean section?

No

Yes (please state how many)

24. What mode of delivery was agreed with the mother/parents? 
25. Did the mother have Mifepristone before induction of labour?

No Mifepristone 200mg once

Other (please specify)

26. Was Misoprostol used for induction of labour? 
27. How many doses of misoprostol were given?

28. What was the timing of the first dose of misoprostol?

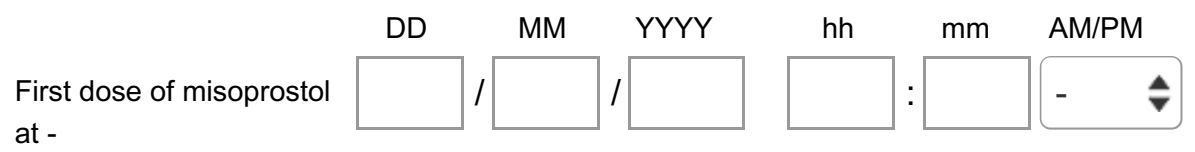

29. Were doses of Misoprostol given as per the North-West Integrated Care Pathway?

Yes

No

If no, please comment / give reasons

30. What analgesia was used in labour (please tick all that apply)?

None

Birthing pool

Entonox

Pethidine

\section{North-West Regional Stillbirth Audit 2016}

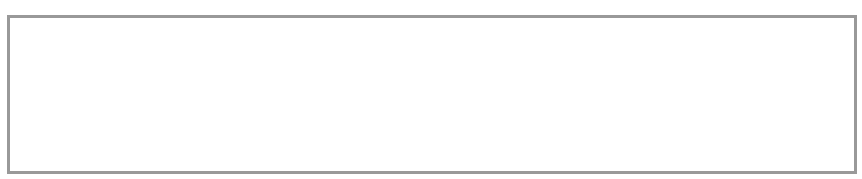

rence please comment/

Other (please specify) 
31. What was the date and time of delivery?

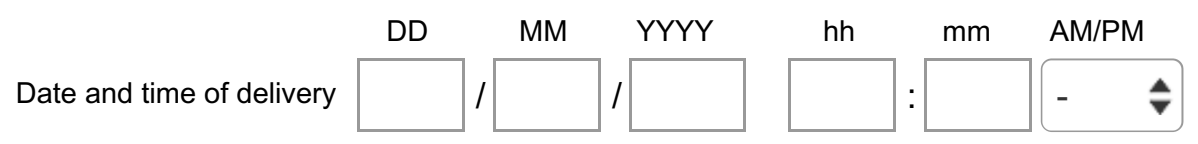

32. What was the gender of the child?
Female
Male
Indeterminate gender

33. What mode of delivery was achieved?

\section{Spontaneous vaginal delivery}

Instrumental vaginal delivery

Caesarean Section

34. What was gestation at delivery? (Please enter weeks + days)

35. What was the birthweight?

Birthweight in grams

36. Was lactation suppression offered?

Yes

No

Contraindicated 
International Journal of Health Governance

Page 30 of 39

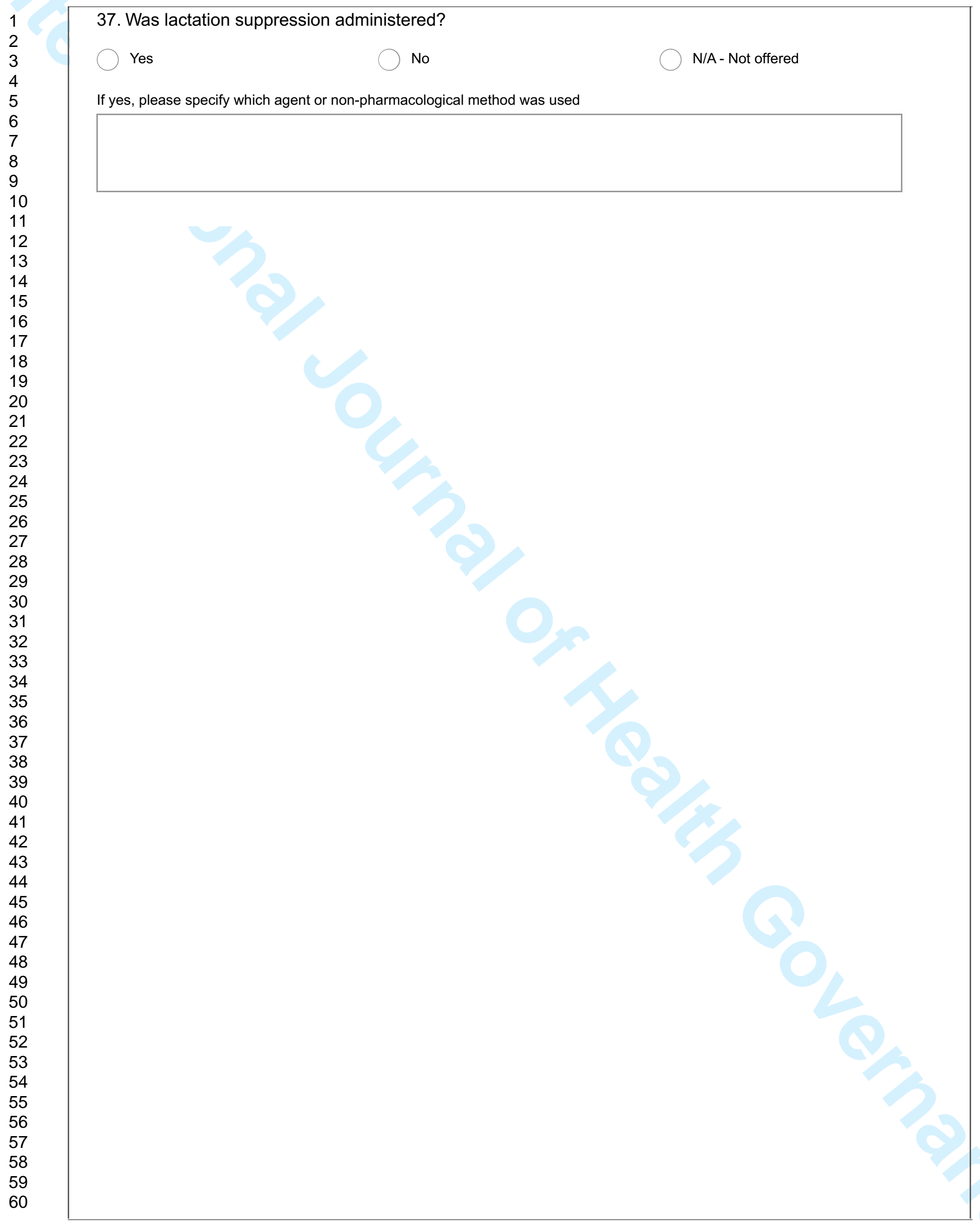




\section{North-West Regional Stillbirth Audit 2016}

\section{Post-mortem}

38. Was a post-mortem leaflet given?
Yes
Not documented

39. Was a Post-mortem offered to the parents?
Yes
No

If no, please document reasons given (e.g. known malformation) 
40. Who counselled parents regarding consent for post-mortem examination?

Midwife

Bereavement Midwife

Obstetrician (ST1-2)

Obstetrician (ST3-5)

Pathologist

Obstetrician (ST6-7)

Other (please specify)

41. Was a post-mortem accepted?

Yes 
North-West Regional Stillbirth Audit 2016

\section{Placental Histology}

42. Was the placenta sent for histology?

Yes 
43. Where was placental histological examination done?

Pathology Dept of Local hospital $O$ Other

Paediatric Pathology Dept, St Mary's Hospital, Manchester

Other (please specify) 
44. Which investigations were performed after delivery of a stillborn baby? (Tick all that apply)

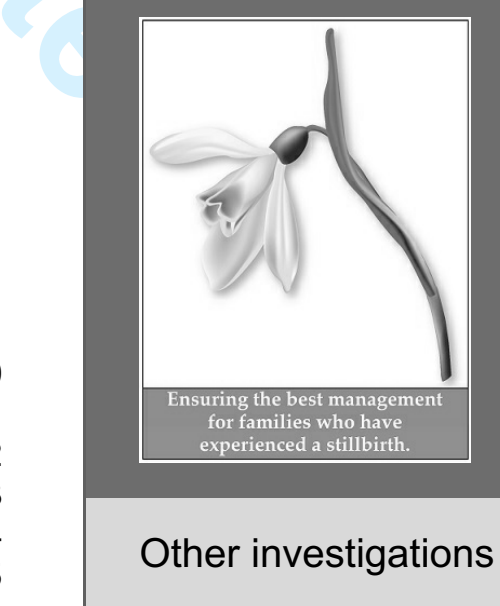

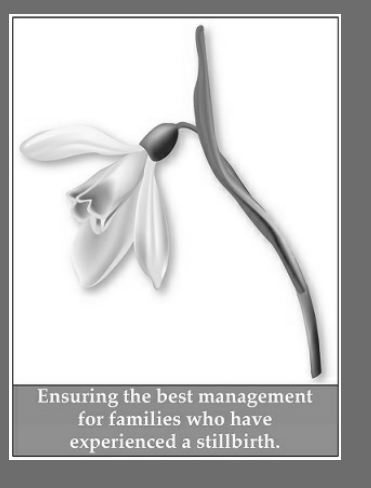

\section{North-West Regional Stillbirth Audit 2016}

\section{$\square$ Cord for microarray}

TORCH screen (Toxoplasma, Rubella, Cytomegalovirus and Herpes Simplex Virus)

$\square$ Parvovirus B19

Bile acids

HbA1c (Glycosylated $\mathrm{Hb})$

Low vaginal swab

\footnotetext{
$\square$ Thyroid function
}

45. Were any other investigations performed?

46. What was the final diagnosis of the cause of death?

47. What other factors were involved or associated with the stillbirth (which results were abnormal)? 


\section{Follow-up / Postnatal Care}

48. Were the mother/parents offered an appointment for follow-up?
Yes
No

49. Did the mother/parents attend for follow-up?

Yes

50. Which professional saw them for follow-up? (Tick all that apply)

$\square$ Consultant

$\square$ Staff-grade doctor

Obstetric trainee (ST6-7)

Obstetric trainee (ST3-5)

Other (please specify)

\section{North-West Regional Stillbirth Audit 2016}

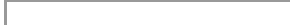

\section{Was contraception discussed?}

Yes

52. Was counselling offered?

Yes 
53. Was a plan for future pregnancy made?

Yes 
54. Was a letter written to the patient?
Yes
No

55. If you have any other comments about this case, please enter them in the box below. 
Thank you very much for completing this survey. We would welcome comments that will help us to develop the guideline and integrated care pathway.

56. Please give us feedback to improve the NW Stillbirth guideline.

57. Please give us feedback to improve the NW Integrated Care Pathway for Stillbirth 